\title{
Classroom Implementation of Active Instructional Strategies for Undergraduate STEM Education
}

\author{
Xin Gao, Member, IACSIT and Brian Schwartz
}

\begin{abstract}
A variety of teaching strategies for undergraduate science, technology, engineering, and mathematics (STEM) educationhave been studied over the years. Most of them are centered at active/collaborative pedagogy. However, most research is focused on introductory, topic courses and very little is targeted at more advanced, calculus based core courses for STEM majors. Even fewer papers provided detailed and sufficient classroom implementation of these strategies. This paper is to fill the gap and provide example strategies and sample assignments for two distinct courses, an introductory science course and an advanced STEM program core course. These strategies shift from traditional lecture-based teaching methods to activity-based methods. According to the Learning Pyramid of the National Training Laboratories of the United States, this shift can increase the average student retention rate from the $10 \%-30 \%$ levels to the $\mathbf{8 0 - 9 0 \%}$ levels. The results on retention rates in this study are consistent with the Learning Pyramid thesis.
\end{abstract}

Index Terms-STEM, undergraduate, education, activities.

\section{INTRODUCTION}

Many efforts have been directed to the improvement of undergraduate STEM education in the United States [1]-[8]. The synopsis of the "Improving Undergraduate STEM Education" program the US National Science Foundation (NSF) has recently implemented says, "A well-prepared, innovative science, technology, engineering and mathematics (STEM) workforce is crucial to the nation's health and economy."

In February 2012, President Obama called to produce one million additional STEM graduates by 2020 . To contribute to the President's call and to meet its own recruiting needs, the United States Navy granted an award to the Business-Higher Education Forum (BHEF) to develop a U.S. STEM Undergraduate Model to show how the Navy's investment strategies in undergraduate STEM education can serve the goal of growing a highly skilled workforce in science, technology, engineering and mathematics [9].

Also, in response to the request of the U.S. Natural Science Foundation, the National Research Council (NRC) implemented a series of two public workshops in 2008 to examine the evidence of impact and effectiveness of selected

Manuscript received April 4, 2014; revised June 25, 2014. This work was supported by the Office of Academic Affairs and the EDIT Grant at the LaGuardia Community College of The City University of New York (CUNY).

Xin Gao is with the Natural Sciences Department, LaGuardia Community College of The City University of New York (CUNY), Long Island City, NY 11101 USA (e-mail: xgao@lagcc.cuny.edu).

Brian Schwartz is with the Physics Department, Brooklyn College of The City University of New York, Brooklyn, NY 11210 USA (e-mail: Bschwartz@gc.cuny.edu). undergraduate STEM education innovations. The selected promising practices after the first workshop include [10]:

- Scenario-, problem-, case-based teaching and learning

- Assessments to guide teaching and learning

- Efforts to restructure the learning environment

- Faculty professional development

In another report of the National Academies National Research Council workshops [11], James Fairweather mentioned that there are different forms of innovative teaching strategies proposed in the past years. However, whether they are called problem-based learning (PBL), case-based learning, ways to build learning communities, or ways to shape professional development programs, most proposed pedagogies still fall in the category of active/collaborative instructional strategies, which we already have many experiences [12]. However, very little work has been done to provide "sufficient formative assessment or a description of implementation steps to help potential adopters put the innovative programs or practices in place".

This paper will fill the gap and provide examples and implementation steps of activities and collaborative instructional strategies used in two distinct classes: one is an introductory/pathway Astronomy course for non-science majors; the other is a calculus-based general physics course for engineering majors.

A major motivation for this research in teaching was to implement the best practice in term of learning illustrated by the Learning Pyramid (see Fig. 1) first created by the National Training Laboratories of the United States [13], [14].

The implementation of innovative teaching strategies in advanced, STEM major core courses along with the most studied, introductory science courses is to provide a showcase for the feasibility of introducing discussions and activities to highly intense, tight-scheduled, less-flexible courses with high math requirements. By introducing these strategies, the retention rates are expected to move up substantially along the learning pyramid.

Before moving on to the activities and strategies used in each class, a brief description of the two distinct courses will be provided in the following section.

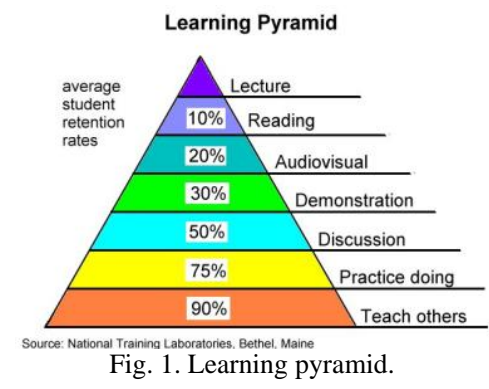




\section{About THE COURSES}

\section{A. Course A: Topics in Astronomy}

This is an introductory/pathway topic course offered to non-science majors as an option in the "Life and Physical Sciences"category. Students' majors range from music,theater, psychology, business, to liberal arts: math and science. There are eighteen chapters to cover in twelve 3 -hour classes. The class meets once a week in a 12 -week semester or twice a week in a 6-week winter/summer semester.

Most of the material covered in this course is easy for students to understand by reading the textbook themselves.

\section{B. Course B: General Physics I}

This is the first part of a series of calculus-based program core coursesforEngineering majors. There are also eighteen chapters to cover in thirty-six 2-hour classes. The class meets 3 times a week. However, the course is not offered in 6-week winter/summer semesters.

Generally speaking, by attending classes and doing in-class exercises, most students can understand most of the materials and are able to do simple one-step problems after each class. But very few students are able to apply the theories or principles flexibly enough to solve complicated problems involving twoor more steps without further practice.

A good number of homework problems have to be assigned to enhance students' understanding and to train students' integrative problem solving abilities.

\section{Methodology}

Activities and collaborative tasks are implemented in different ways in each class. However, different forms of activities serve for the same goals: to engage, motivate students, and make teaching more effective. Following are selected strategies used in both classes, followed by a discussion of the skills and abilities students can practice through these activities.

\section{A. Strategy 1: In-Class or Outside-of-Class Discussions}

\section{1) Course A: Topics in astronomy}

Each discussion in this course isbased on a reading assignment of one or more chapters of the textbook. Detailed reading assignments with questions and required tasks are usually distributed to students at least one week before the discussions. Students are required to finish the reading assignment before eachdiscussion session. At the end of a discussion session, students are asked to present their opinions or sometimes their work, depending on the requirements of the assignment, in front of the whole class.

In a class when a discussion takes place, students work in small groups, which usually include four or less students. Different students may play different roles: leader, note-taker, researcher, presenter, etc. Each group may decide to present together with each team member responsible for a small part, or to appoint one student as the presenter for one discussion and take turns within the group over the semester.

At the end of the discussion, students are asked to grade each of their group members' contribution and to grade other groups' presentation as well. By doing this, students are motivated to participate actively and maximize their contributions to theirgroups.

The instructor will also grade the groups and then assign a grade to each student according to his/her performance inside the group and the average grade of his/her group as a whole.

\section{2) Sample reading assignment}

Please read Chapter 7, 18 and the three articles posted on Blackboard to prepare for next week's in-class discussion. Please keep the following questions in your mind when reading these materials:

1) Discuss the range of environments in which life thrives on Earth. What are the basic requirements apply to life in all these environments?

2) What is a habitable world? What does a star's habitable zone mean? What's your opinion about the possible number of stars to be capable of having habitable planets in the universe?

3) Referring to Paper \#1, what kind of conditions do you suggest studying first to decide the possibility of life on the "Earth twin/cousin"?

4) Referring to Paper \# 2, what is the current status of the search for life on Mars?

5) What makes it so hard to find ideal planets for lives to survive on them? What makes Earth so special when compared with other planets, such as Venus and? What is special for Earth's atmosphere?

6) The climate conditions on other terrestrial planets, especially those of Venus and Mars make it clear that it's not "easy" to get a pleasant climate like that of Earth. How does this affect your opinion about the following issues: climate change, global warming, or the loss of species on earth due to human activities? What recommendations do you make about what, if any, needs to be done to prevent further damage? [15], [16].

7) One of the most important public discussions today is about the role of human in altering Earth's climate. Are you an advocate or skeptic of human beings causing climate change? What evidences do you have to support your opinion?

Students were highly engaged in this discussion session. 18 out of 18 students shared their opinions with fellow students and actively participated in the discussion. By participating in discussions in a classroom, students were required to do research on a given topic, discuss their opinions with fellow students, and sometimes practice and teach others. All these are practices with higher average retention rate according to the Learning Pyramid thesis.

\section{3) Course B: General physics I}

Discussions in this course cannot be implemented in the same way as discussions in Course A due to the intensity of the calculus-based physics course and the tight schedule. It is impossible to occupy any in-class time to do discussions at a significant frequency.

Considering these limitations, adjustments were made such that adopted technologies would make online discussions as lively and effective as in-class ones.

Similar to the in-class discussions for Course A, online discussions for Course B are also problem-based. Detailed description of a problem will be posted online about two 
weeks before the discussion. Students are free to use all possible resources available to them. The difference is that instead of working in teams, students participate the discussions individually by posting or responding to others' initial posts.

Grades are given according to the number of posts each student makes and the quality of the posts.

This strategy can be easily changed to accommodate group discussions. In that case, the grading method used in Course A will be applied.

\section{4) Sample problem used for discussion}

Please design an experiment to predict the horizontal distance traveled by a small metal ball after it rolls down a table. You are required to do multiple trials to find the average distance in the horizontal direction. Suppose you are able to approximately measure the instantaneous velocity of the metal ball when it leaves the table. You will be provided with a meter stick, a marked track, a marker, carbon paper, regular paper and some tape. If you need any extra apparatus, please specify and explain why.

Please design your experiment in a way that the multiple trials do not vary violently, which means that the landing spotsof the small metal ball will be close to each other.

For discussions in both courses, grading rubrics are set and made known to students at the beginning of the semester.

Goals and skills involved in instructional strategy1 (Discussions) include:

- Inquiry and problem solving abilities. These skills are practiced when students prepare for the discussion. They need to study the problem, search for information and finally find a solution to the problem.

- Communication skills: interpersonal communication skills are practiced when students work together in groups; public speaking and presentation skills are practiced when students present their opinions to the whole class.

- Global Learning: some topics have global interests, e.g. global warming. Students are encouraged to take an international perspective and find solutions that may require cooperation among different nations and governments.

\section{B. Strategy 2: Hands-on Activities}

\section{1) Course A: Topics in astronomy}

Due to limited resources, there are no formal lab sessions for Course A. So topic-related hands-on activities are designedto engage students, train students' problem solving abilities and enhance students'understanding of the course work, especially for topics with technical elements involved.

In these activities, students are asked to work in teams and will be evaluated as a team as well. Same asforStrategy 1, students are asked to grade their team members to encourage active participation, but they do not need to grade other groups' work in this strategy.

\section{2) Sample hands-on activity}

Make your own solar system by scaling down both the sizes of the sun and its planets and the distances between the planets and the sun.

In your solar system, you may only include the three closest planets: Mercury, Venus and the Earth due the large distances from other further planets to the sun. Even though, you will find it's still impossible to fit all the planets and the sun on a large-sized paper. To address this problem, please feel free to use different scales for the size of the sun, the sizes of the planets and the distances from the planets to the sun. Accordingly, you have to label or explain in words thedifferent scales you use for different dimensions to make other people understand your "modified" solar system.

This activity was the first activity of this course. Non-science-major students are usually intimidated by math, especially calculations with large numbers (scientific notations) and unit conversions. For example, the sun's radius is given as $695,000 \mathrm{~km}$. Students were asked to convert the unit from kilometer to meter first, then scale down to several centimeter in order to fit the size of the sun in a piece of $45 \mathrm{~cm} \times 60 \mathrm{~cm}$ paper. In addition, the sizes of planets and distances from planets to the sun need to be scaled down using different scales. All these make the activity a little hard for non-science-major students. But the fact that they have to adjust their scales to fit the whole solar system in a large piece of paper makes students better understand the sizes of different objects in the solar system and the distances among them.

\section{3) Course B: General physics I}

Unlike course A, there are formal and well-organized lab sessions for course B. A lab manual for each experiment is distributeto students before everylab session. Students are asked to read the lab manual and get some general ideas about the experiment before they come to class.

At the beginning of each lab session, amini-lecture about the theory behind the experiment and the procedures of the experiment will be explained first. Students are asked to do experiments in teams. Team members may share same data, but the data analysis and lab report are required to finish individually and will be graded individually.

\section{4) Sample lab session}

The goal of this experiment is for students to learn adding two or more vectors on a 2-Dimensional force table. By balancing the force table, students will practice how to combine two vectors to get the magnitude and direction of the net vector experimentally.Students are then asked to compare their results from experiments with the calculated theoretical values from the following formulas:

$$
\begin{gathered}
F_{n e t}=\sqrt{F_{x}^{2}+F_{y}^{2}} \\
\theta=\tan ^{-1}\left(\frac{F_{y}}{F_{x}}\right)
\end{gathered}
$$

This lab session served as a supplement of the topic: "Vectors", which is an abstract concept in physics. Students usually found it hard to understand the different rules used in adding vectors than adding numbers. By this lab session, students learned adding vector through practice doing. The process enhanced their understanding of vectors and made them understandbetter why directions count so much in adding vectors.

Goals and Skills involved in instructional strategy 2 (Hands-On Activities):

- Problem solving abilities are also practiced when students 
try to finish a well-designed task.

- Quantitative/Math skills: Activities designed in this strategy usually have technical elements involved. Students are exposed to problems requiring quantitative or math skills.

- Integrative ability: Activities designed in this strategy are usually comprehensive and have more than one skill sets involved. Students need to integrate knowledge they acquired from different courses or different parts of one course to solve the problem.

\section{Strategy 3: Using Technology in Classroom}

\section{1) Course A: Topics in astronomy}

Visual experiences are especially important for Astronomy courses. Besides pictures and simulations the textbook provides, an extensive resource of tools and applications were explored to facility the effective teaching and learning of the Astronomy course.

Examples include Google sky, which is still under development, but already show substantial potential as a 3D tool to explore the planets of the solar system, theMilky Way galaxy, or even the whole universe.

In this course, simulations, visual demonstrations and videos are incorporated into classes directly. For example, the most recent TV show "Cosmos" provides a spectacular visual experience in many topics of Astronomy.Episodes of the show wereselected and used in a way that supplements the lectures or discussions ongiven topics.

\section{2) Sample class with technology involved}

In response to students' interests in the recent TV show Cosmos: A space-time Odyssey. Episode 8 (Sister of the Sun) of the show was introduced in class as a supplement of the topic: "Stars". After the 45 minutes show, students wereeager to share their opinions with their classmates. At the same time, they also had some questions to ask about the topic. Questions were collected and posted on Blackboard. Before the next class session, students were encouraged to select and answer any number of these questions until all questions were answered. Students were not allowed to answer questions which were already answered by other students based on a "first come, first pick" policy. Students got one extra credit for each question they answered correctly.Students were asked to explain their answers to fellow students in the following class session. After this, a mini-discussion was held and students were asked to share their opinions with their fellow students about: What do they think of the show? Does the show help better visualize our solar system? What new information, which is not covered in the textbook or lecture, do they acquire from the show, etc.?

This kind of discussion after watching a video or other visual aids is different from the discussions mentioned in strategy 1 . In this kind of discussion, students get more motivation to ask questions that interests them. Instead of passively listening to a lecture, they are asked to take part in the design of the class. Their questions will affect the contents and direction of the topic, which serves better for their interests.

\section{3) Course B: General physics I}

The purposes of using videos or simulations in course B are different from those in course A. Incorporating technologies in course $\mathrm{A}$ is an important and effective strategy to engage students, to help visualize otherwise hard-to-picture phenomena, or sizes or arrangements of objects in space, etc. However, the use of technology in course $\mathrm{B}$ is to demonstrate the application of a certain concept, law, or principle.

With these differences in mind, videos and simulations used in course B should be more specific and focused. Due to the tight schedule of these advanced courses, the videos and simulations should also be short and to the points.

\section{4) Sample videos/simulations used in course}

When talking about transverse waves, two motions in perpendicular directions are involved at the same time, e.g. the waves in a rope. It is not easy for students to understand that each point on the rope is just doing up and down motion, but the wave pattern is traveling along the rope.

By introducing a simulation application, where a white board serves as the time line when moving along the line perpendicular to the oscillation, students clearly see that the oscillator only moves up and down. As time goes, energy can be transmitted through the medium and cause other points to move up and down, through which a wave pattern is formed.

Students were highly engaged by the simulation application. They automatically suggested changing parameters in the simulation so as to see other scenarios when the initial oscillating conditions are changed.

Goals and skills involved in instructional strategy 3 (Using Technology in Classroom) include:

- Appropriate use of technologies in classroom can help engage students, activate teaching and learning and effectively help explain complicated concepts and theories.

- Students are exposed to digital communication methods and encouraged to practice digital communication skills in their own presentations.

\section{CONCLUSION}

In this paper, a number of active instructional strategies for undergraduate STEM education were discussed with sufficient results from the implementation processes in actual classroom situations. It has been shown that these strategies can be applied to both introductory science courses and advanced STEM program core courses. The following goals have been achieved:

1) Successful learning results in both the introductory topic science courses and advanced STEM program core courses.

2) Demonstrated the positive difference between the implementations of active instructional strategies in these two different types of science courses mentioned above as compared to traditional lecture-based learning.

3) Identified through testing in a classroom situation a number of active instructional strategies that can be applied to both introductory topic science courses and advanced STEM program core courses.

4) Better-engaged students by shifting from traditional lecture-based teaching methods to activity-based teaching methods. Students' involvements in class were substantially increased. 
5) Provided sufficient details in the methodology of implementing activity-based teaching methods for both types of science courses, which should enable replication of the strategy at other institutions.

6) Increased the average student retention rate from the $10 \%-30 \%$ levels to the $80-90 \%$ level according to the Learning Pyramid thesis of National Training Laboratories of the United States.

\section{PROPOSAL FOR FUTURE WORK}

Future efforts will be directed to develop quantitative assessment methods by giving pre-tests and post-tests to evaluate the effectiveness of different teaching strategies. The author has applied for grants to support this research.

\section{ACKNOWLEDGMENT}

The author would like to thank the Office of Academic Affairs and the EDIT grant of the LaGuardia Community of The City University of New York (CUNY) for supporting this research.

\section{REFERENCES}

[1] R. Barr and J. Tagg, "From teaching to learning: A new paradigm for undergraduate education," Change, vol. 27, pp. 12-15, 1995.

[2] Transforming Undergraduate Education in Science, Technology, Engineering and Mathematics, $1^{\text {st }}$ ed., Washington, DC: National Academy Press, 1999, ch. 1, pp. 21-60.

[3] C. Colbeck, K. O'Meara, and A. Austin, Educating Integrated Professionals: Theory and Practice on Preparation for the Professoriate, $1^{\text {st }}$ ed., San Francisco, CA: Jossey- Bass, 2008, ch. 6, pp. 69-80.

[4] D. Fisher, J. Fairweather, and M. Amey, "Systemic reform in undergraduate engineering education: The role of collective responsibility," International Journal of Engineering Education, vol. 19, pp. 768-776, 2003.

[5] K. A. Smith, T. C. Douglas, and M. F. Cox, "Supportive teaching and learning strategies in STEM education," New Directions for Teaching and Learning, no. 117, pp. 19-32, 2009.

[6] D. Johnstone and P. Mahoney, "Enhancing the productivity of learning: Curricular implications," New Direction for Higher Education, vol. 26, pp. 23-34, 1998.

[7] R. MacDonald and L. Korinek, "Cooperative learning activities in large entry-level geology courses," Journal of Geological Education, vol. 43, pp. 341-345, 1995.
[8] K. A. Smith, S. D. Sheppard, D. W. Johnson, and R. T. Johnson, "Pedagogies of engagement: classroom-based practices," Journal of Engineering Education, vol. 94, pp. 87-101, 2005.

[9] The U.S. STEM Undergraduate Model: Applying System Dynamics to Help Meet President Obama's Goals for One Million STEM Graduates and the U.S. Navy's Civilian STEM Workforce Needs, Business-Higher Education Forum (BHEF), $1^{\text {st }}$ ed. Washington, DC, 2013, pp. 4-21.

[10] N. Nielsen, Promising Practices in Undergraduate Science, Technology, Engineering, and Mathematics Education: Summary of Two Workshops, National Academy of Sciences, $1^{\text {st }}$ ed. Washington, DC: The National Academies Press, 2011, ch. 4, pp. 26-34.

[11] J. Fairweather, "Linking evidence and promising practices in science, technology, engineering, and mathematics (stem) undergraduate education," presented at the National Research Council Workshop on Linking Evidence and Promising Practices in STEM Undergraduate Education, Washington, DC, October 13, 2008.

[12] G. Kuh, J. Kinzie, J. Schuh, and E. Witt, Student Success in College: Creating Conditions That Matter, $1^{\text {st }}$ ed., San Francisco, CA Jossey-Bass, 2005, ch 8-12, pp. 177-260.

[13] E. Dale, Audiovisual Methods in Teaching, $3^{\text {rd }}$ ed., New York, NY: Dryden Press, 1969, ch. 2, pp. 37-50.

[14] N. DeKanter, "Gaming redefines interactivity for learning," TechTrends: Linking Research \& Practice to Improve Learning, vol. 49, no. 3, pp. 26-31, 2005.

[15] J. Bennett, M. Donahue, N. Schneider, and M. Voit, The Essential Cosmic Perspective, $6^{\text {th }}$ ed., White Plains, NY: Addison-Wesley, ch. 7, pp. 233, 2012.

[16] S. Chen, B. Mulgrew, and P. M. Grant, "A clustering technique for digital communications channel equalization using radial basis function networks," IEEE Trans. on Neural Networks, vol. 4, pp. 570-578, July 1993.

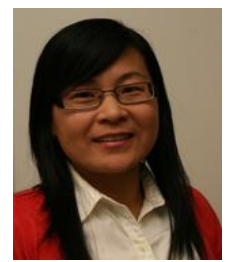

Xin Gao obtained her Ph.D. in physics from the Graduate Center of The City University of New York (CUNY). Her PhD thesis was focused on the interface of physics, mathematics, and finance. In that research she used techniques from mathematics and physics to develop pricing models for financial derivatives. The work was presented at the 2011 International Conference on Applied Mathematics, Modeling and Computational Science. Dr. Gao also has rich research experience in experimental physics and has published her work in different peer-reviewed journals.

Before joining LaGuardia Community College of the City University of New York, Dr. Gao worked as an adjunct assistant professor at the Fashion Institute of Technology of the State University of New York (SUNY), Baruch College and Borough of Manhattan Community College of The City University of New York. At present, she is focusing on pedagogical research on undergraduate STEM education.

She published several articles, such as: X. Gao "AnAnalytical Solution to the pricing of a two-category heterogeneous collateralized debt obligations", working paper, and so on. 